\title{
STUDI ANALISIS KEMAMPUAN PENYEDIAAN SUPLAI DAYA AKIBAT PENINGKATAN BEBAN DI GARDU INDUK NUSA DUA
}

\author{
Nur Ayu Puspita Indra Pratiwi ${ }^{1}$, I Gede Dyana Arjana ${ }^{2}$, Antonius Ibi Weking ${ }^{3}$ \\ Program Studi Teknik Elektro, Fakultas Teknik Universitas Udayana \\ Email : aiirynayu@gmail.com ${ }^{1}, \underline{\text { dyanaarjana@unud.ac.id }}{ }^{2}$, tony@unud.ac.id ${ }^{3}$
}

\begin{abstract}
ABSTRAK
Wilayah Bali Selatan merupakan objek wisata yang memiliki banyak bangunan hotel, vila, dan sektor pariwisata serta sebagai tempat pelaksanaan acara Nasional dan Internasional. Menyebabkan beban pada Gardu Induk Nusa Dua akan meningkat. Seiring dengan perkembangan beban, Gardu Induk Nusa Dua harus mampu di suplai dari GIS Bandara dan GIS Pesanggaran. Prakiraan beban menggunakan regresi linear untuk memperoleh nilai perkembangan beban Transformator dan suplai daya hingga 5 tahun mendatang.

Hasil perhitungan laju pertumbuhan beban Transformator Gardu Induk Nusa Dua adalah 8,9\% pertahun, dan hasil perhitungan tahun 2018 pada Transformator 1 sebesar 113,38A Transformator 2 sekitar 124,3A, dan Transformator 3 sebesar 137,09A. Hasil perhitungan laju partumbuhan suplai daya melalui transmisi $150 \mathrm{Kv}$ menuju Gardu Induk Nusa Dua yaitu 179,612A yang disuplai dari GIS bandara, dan 238,32A dari GIS Pesanggaran. Selisih antara beban dan suplai daya pada tahun 2018 sebesar 18,53A $(0,430 \%)$ dari GIS Bandara dan 24,53A (0,570\%) dari GIS Pesanggaran. Transformator 3 pada tahun 2025 tidak mampu mensuplai beban, Transformator 2 tidak mampu mensuplai beban pada tahun 2026, dan Transformator 1 tidak mampu mensuplai beban pada tahun 2027. Sehingga diperlukan penambahan Transformator baru atau pembangunan Gardu Induk baru di sekitar wilayah peningkatan beban.

Kata Kunci : Transformator, kenaikan beban, suplai daya.
\end{abstract}

\section{ABSTRACT}

The area of South Bali is a tourist attraction that has many hotel buildings, villas, and tourism sector as well as a venue for the implementation of National and International events. Causing the burden on the Nusa Dua Main Entity will increase. Along with the load development, Nusa Dua Substation must be able to supply from GIS Airport and GIS Pesanggaran. Forecast load using linear regression to obtain the value of the development of the transformer load and power supply up to 5 years.

The calculation of the growth rate of the transformer load of the Nusa Dua Substation Transformer is $8.9 \%$ per year, and the calculation of 2018 in Transformer 1 is 113.38A Transformer 2 about 124.3A, and the Transformer 3 is 137.09A. The calculation results of the growth rate of power supply through the transmission of $150 \mathrm{KV}$ to the Nusa Dua Substation is $179,612 A$ supplied from GIS airport, and 238.32A from GIS Pesanggaran. The difference between load and power supply in 2018 is $18.53 \mathrm{~A}(0.430 \%)$ of GIS Airport and $24.53 \mathrm{~A}(0.570 \%)$ of GIS Pesanggaran. Transformer 3 in 2025 is not capable of carrying the load, Transformer 2 can not loads in 2026, and Transformer 1 is not able to the burden in 2027. So that required the addition of new Transformer or construction of new substation in the area of increasing load.

Keywords: growth rate, power supply, transformer.

\section{PENDAHULUAN}

Pulau Dewata Bali merupakan wilayah Indonesia yang sudah terkenal hingga mancanegara dalam sektor pariwisata, ini terlihat dari pertumbuhan pembangunan yang tinggi. Pembangunan yang terus 
menerus terjadi tentu saja memicu kebutuhan energi listrik. Setiap tahunnya jumlah kebutuhan listrik terus meningkat, secara tidak langsung beban transformator terus bertambah sehingga transformator tidak mampu lagi untuk memikul beban yang melebihi dari kemampuan transformator tersebut. Setiap transformator tentu mempunyai tingkat kemampuan yang berbeda-beda sesuai dengan jumlah beban yang dilayani. Setiap tahunnya jumlah pelanggan terus meningkat, otomatis beban transformator terus bertambah sehingga seiring berjalannya waktu transformator tidak mampu lagi untuk memikul beban yang sudah melebihi batas kemampuan transformator tersebut. Sehubungan dengan ini penelitian dilakukan untuk dapat mengetahui berapa lama transformator mampu memikul beban yang selalu meningkat di wilayah Nusa Dua.

\section{KAJIAN PUSTAKA}

\subsection{Sistem Transmisi Tenaga Listrik}

Transmisi tenaga listrik merupakan proses penyaluran tenaga listrik dari power plan sampai substation sehingga dapat disalurkan sampal pada konsumen pengguna tenaga listrik melalui konduktor [1]. Keuntungan transmisi dengan tegangan lebih tinggi akan menjadi jelas jika melihat pada kemampuan transmisi suatu saluran. Kemampuan ini biasanya dinyatakan dalam Mega Volt Amper (MVA) [2].

\subsection{Analisa Aliran Daya}

Kehandalan sistem dalam tenaga listrik sangat diperlukan. Agar kehandalan sistem dapat diestimasikan maka diperlukan suatu sistem analisis yang memudahkan dan mempercepat penelitian terhadap masalah-masalah yang ada. Dengan adanya sistem analisis ini maka akan mempercepat ditemukan solusi yang lebih baik dalam melaksanakan operasi sistem tenaga listrik [3].

\subsection{Transformator}

Transformator adalah suatu peralatan tenaga listrik yang berfungsi untuk menyalurkan tenaga/daya listrik dari tegangan tinggi ke tegangan rendah atau sebaliknya [4]. Dalam operasi penyaluran tenaga listrik, transformator dapat dikatakan sebagai jantung dari transmisi. Dalam kondisi ini transformator diharapkan dapat beroperasi secara maksimal [5].

\subsection{Peramalan Beban}

Penerapan statistik untuk memperkirakan kebutuhan energi listrik di masa yang akan datang merupakan salah satu cara yang tepat untuk mendapatkan hasil perhitungan yang mendekati sebenarnya. Metode peramalan dalam memprediksi daya adalah analisa kecendrungan (trend), yaitu cara mempelajari data dalam sederet waktu atau suatu proses di waktu yang lalu, kemudian dibuat model matematis sehingga prediksi yang akan datang dapat diketahui dari sekarang. Dalam peramalan beban listrik, komponen yang termasuk dalam beban listrik adalah jumlah pelanggan listrik, konsumsi energi listrik, beban yang tersambung, dan beban rata-rata dalam bentuk persamaan matematis perkembangan beban listrik [6] yang secara umum dapat dinyatakan oleh Persamaan (1).

$$
y=a+b x
$$

Agar mendapatkan konstanta a dan b dilakukan dengan menggunakan regresi linier yang disebut regresi least square line dan dinyatakan dalam Persamaan (2).

$$
\sum_{i-1}^{N}\{Y f(X i)\}=\text { mnimum }
$$

Jika persamaan linier yang digunakan untuk memperkirakan perkembangan beban listrik di masa yang akan datang didefinisikan $y_{x}=a+b_{x}$ dan data hasil observasi dinotasikan dengan $Y_{i}$ maka kesalahan yang terjadi dari hasil penelitian dengan data hasil persamaan regresi dapat dibuat seminimum mungkin [6], yaitu dengan mengambil 1 kuadrat kesalahan mendekati nol yang dinyatakan dalam Persamaan (3) dan(4)

$$
\begin{aligned}
& (\text { error })^{2}=\sum\left(y_{i}-y x\right)_{i-1}^{n_{2}}=0 \\
& \mathrm{a}=\frac{\sum_{i-1}^{n} y_{i}-b \sum_{i-1}^{n} x_{i}}{n}
\end{aligned}
$$

dan untuk harga $b$ dihitung menggunakan Persamaan (5).

$$
b=\frac{n \sum x_{i} y_{i}-\sum y_{i} \times \sum x_{i}}{n \sum x_{i}^{2}-\left(\sum x_{i}\right)^{2}}
$$

Setelah nilai $a$ dan $b$ diperoleh, maka persamaan linier dapat digunakan untuk 
memperkirakan perkembangan beban listrik di tahun yang akan datang. Besar persentase kesalahan dapat dihitung dengan Persamaan (6) [7].

$$
\begin{aligned}
& \% \text { kesalahan }= \\
& \frac{\text { data beban-data perhitungan }}{\text { data perhitungan }} \times 100 \%
\end{aligned}
$$

Sehingga kenaikan beban setiap tahunnya sapat dihitung dengan Persamaan (7).

kenaikan beban $=$ prediksi beban

tahun ke - nx $100 \%$ beban

\subsection{Kemampuan Hantar Arus}

Kemampuan hantar arus penghantar adalah kemampuan dari suatu penghantar untuk mengalirkan arus dengan nilai tertentu secara terus menerus pada kondisi tertentu tanpa menimbulkan kenaikan suhu yang melebihi nilai tertentu. Secara umum sumber panas dalam konduktor dibagi menjadi dua yaitu panas yang dihasilkan oleh konduktor yang dialiri arus dan panas yang dihasilkan oleh isolasi akibat terpaan medan listrik. Konduktor saluran transmisi mempunyai ukuran luas penampang inti konduktor yang berhubungan dengan kapasitas penghantar arus listriknya [8]. Besarnya kapasitas hantaran konduktor dinamakan dengan kuat hantar arus. Kemampuan hantar arus adalah suatu penghantar dibatasi dan ditentukan berdasarkan batasan-batasan dari aspek lingkungan [9].

\section{METODELOGI PENELITIAN}

Diagram alur Gambar 1, dalam penelitian ini dilakukan dalam beberapa tahapan, yaitu:

1. Mengumpulkan data-data teknis seperti data beban puncak sstem kelistrikan Nusa Dua, data spesifik saluran $150 \mathrm{kV}$ yang disuplai menuju Gardu Induk Nusa Dua, dan data Transformator.

2. Menghitung persentase laju pertumbuhan beban.

3. Menghitung kemampuan beban transformator dalam memikul beban yang terus meningkat.

4. Menghitung beban saluran $150 \mathrm{kV}$ yang disuplai ke GI Nusa Dua pada tahun 2018-2022 dan beban transformator.

5. Menganalisis pengaruh beban terhadap saluran.

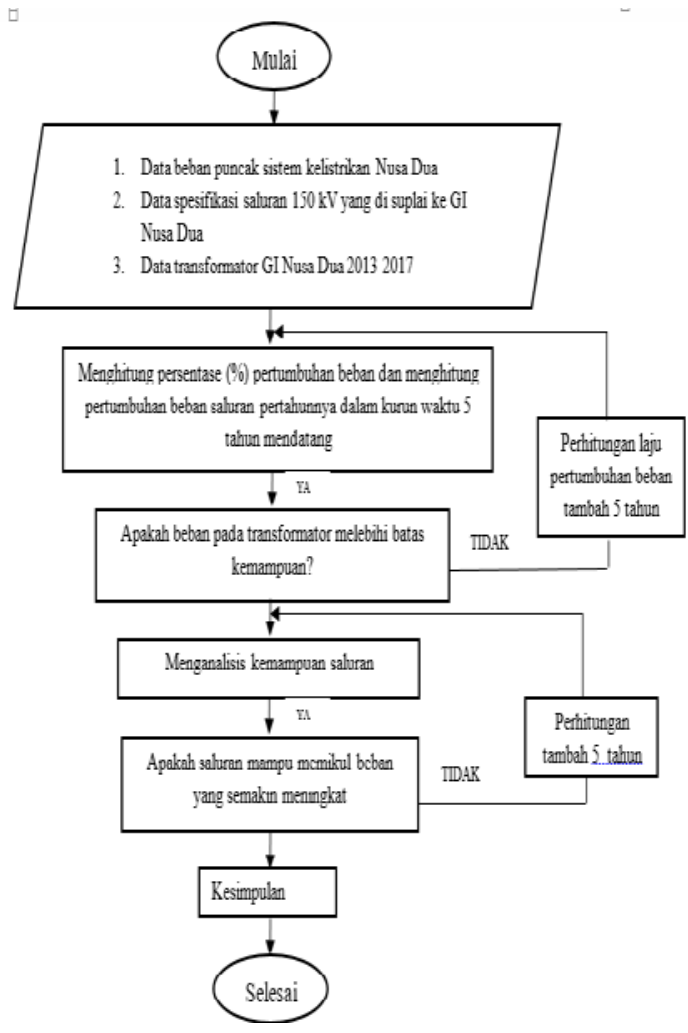

Gambar 1. Diagram Alur Analisis

\section{HASIL DAN PEMBAHASAN}

4.1 Gambaran Umum Gardu Induk Nusa Dua

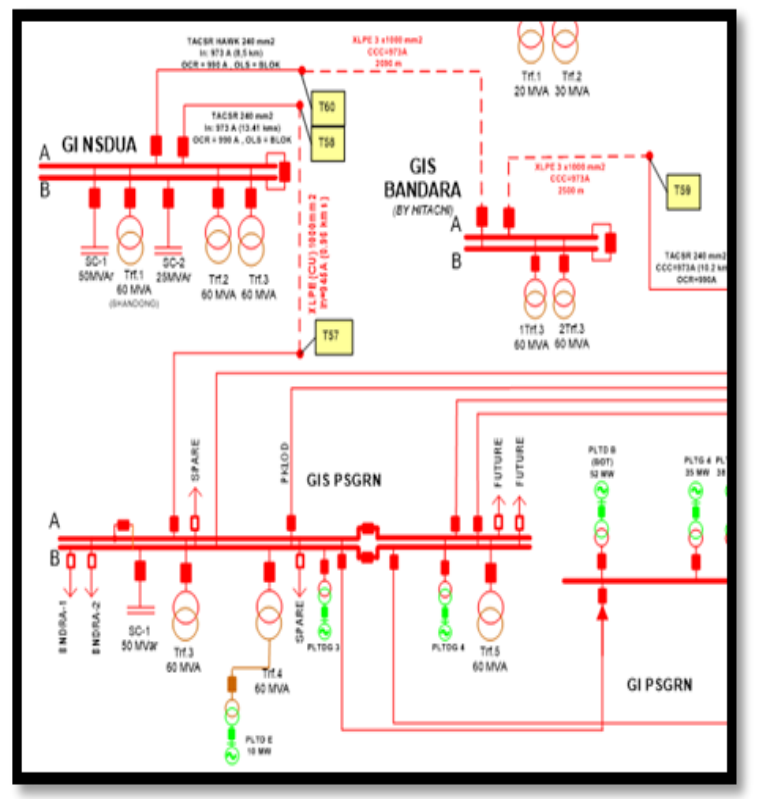


Gambar 2. Sub Sistem 150 kV Gardu Induk Nusa Dua

Secara umum Gardu Induk Nusa Dua ditunjukkan pada Gambar 2. Gardu Induk Nusa Dua memiliki 3 buah transformator yang berfungsi sebagai alat untuk mengubah tegangan agar dapat disuplai ke saluran distribusi. Pada ketiga transformator tersebut memiliki beban maksimal yang sama yaitu 230 A dengan kapasitas yang sama yaitu 60 MVA. Gardu Induk Nusa Dua mendapat pasokan beban dari GIS Bandara dan GIS Pesanggaran yang masing-masing menggunakan penghantar berjenis TACSR $240 \mathrm{~mm}^{2}$ dan XLPE $3 \times 1000 \mathrm{~mm}^{2}$.

4.2 Perhitungan Persentase Laju Pertumbuhan Setiap Tahunnya

Laju pertumbuhan beban dihitung menggunakan persamaan (5).

$$
\begin{aligned}
b & =\frac{n \sum x_{i} y_{i}-\sum y_{i} \times \sum x_{i}}{n \sum x_{i}^{2}-\left(\sum x_{i}\right)^{2}} \\
& =\frac{5(883330,00)-4416205}{101505675-101505625} \\
& =\frac{445,03}{50} \\
& =8,9 \%
\end{aligned}
$$

Laju pertumbuhan beban puncak transformator dan suplai daya menuju Gardu Induk Nusa Dua 8,9\% pertahun.

\subsection{Perhitungan Pertumbuhan Beban Transformator}

Tabel 1. Data beban transformator

\begin{tabular}{|c|c|c|c|}
\hline \multirow{2}{*}{ TAHUN } & \multicolumn{3}{|c|}{ Beban (A) } \\
\cline { 2 - 4 } & TRAFO I & TRAFO II & TRAFO III \\
\hline 2013 & 74,80 & 73,37 & 149,55 \\
\hline 2014 & 71,03 & 96,33 & 109,91 \\
\hline 2015 & 85,96 & 106,43 & 95,56 \\
\hline 2016 & 103,45 & 107,23 & 99,48 \\
\hline 2017 & 103,093 & 109,831 & 102,41 \\
\hline
\end{tabular}

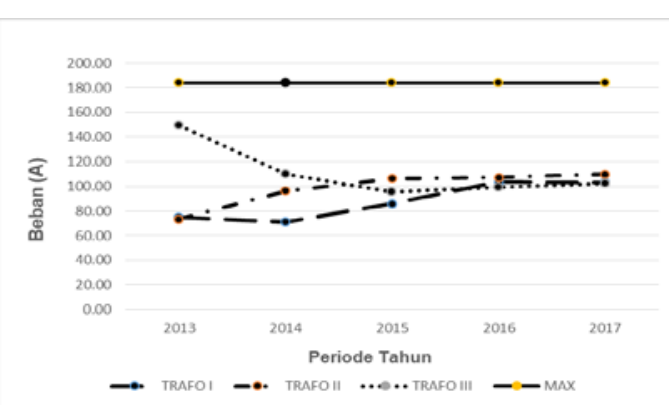

Gambar 3. Grafik data pertumbuhan beban tahun 2013-2017

Tabel 1 dan Gambar 3 merupakan grafik data laju pertumbuhan beban Gardu Induk Nusa Dua pada tahun 2013-2017. Pada Gambar 3 telihat bahwa beban tidak selalu mengalami peningkatan namun juga mengalami penurunan yang disebabkan oleh faktor-faktor tertentu.

Nilai perkembangan beban listrik pada tahun tahun pertama dihitung menggunakan persamaan (4).

$$
\begin{aligned}
a & =\frac{\sum_{i-1}^{n} Y_{i}-B \sum_{i-1}^{n} X_{i}}{n} \\
& =\frac{438,333-8,9(10075,00)}{5} \\
& =\frac{438,333-89673,54}{5} \\
& =\frac{-89235,21}{5} \\
& =-17847,042
\end{aligned}
$$

Berdasarkan hasil perhitungan laju pertumbuhan transformator menggunakan regresi linear diperoleh persamaan $Y=$ $17847,042+8,9 x$. Dari persamaan tersebut dapat dicari beban tiap tahunnya menggunakan persamaan (1) dan hasil perhitungan sampai tahun 2027 ditunjukkan pada Tabel 2.

$$
\begin{aligned}
Y & =a+b x \\
& =-17847,042+8,9(2018) \\
& =-17847,042+17960,2 \\
& =113,38 A
\end{aligned}
$$

Tabel 2. Hasil perhitungan pertumbuhan beban ransformator Gardu Induk Nusa Dua menggunakan metode regresi linear

\begin{tabular}{|c|c|c|c|}
\hline \multirow{2}{*}{ TAHUN } & \multicolumn{3}{|c|}{ BEBAN TRANSFORMATOR A } \\
\cline { 2 - 4 } & Trafo 1 & Trafo 2 & Trafo 3 \\
\hline 2018 & 113,38 & 126,43 & 137,09 \\
\hline 2019 & 121,95 & 135,02 & 145,66 \\
\hline 2020 & 130,52 & 143,61 & 154,23 \\
\hline
\end{tabular}




\begin{tabular}{|c|c|c|c|}
\hline 2021 & 139,09 & 152,20 & 162,80 \\
\hline 2022 & 147,66 & 160,79 & 171,37 \\
\hline 2023 & 156,23 & 169,38 & 179,94 \\
\hline 2024 & 164,80 & 177,97 & 188,51 \\
\hline 2025 & 173,37 & 186,56 & 197,08 \\
\hline 2026 & 181,94 & 195,15 & 205,65 \\
\hline 2027 & 190,51 & 203,74 & 214,22 \\
\hline
\end{tabular}

kapasitas

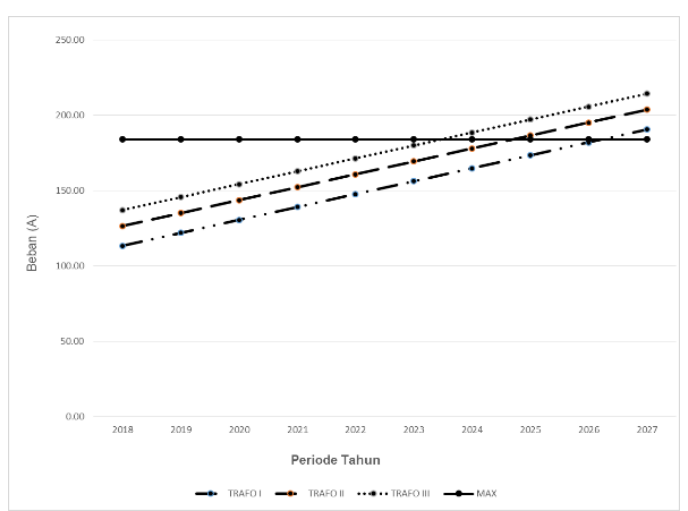

Gambar 4. Grafik hasil perhitungan pertumbuhan beban transformator tahun 20182027

Gambar 4 merupakan grafik hasil perhitungan laju pertumbuhan beban transformator pada tahun 2018-2027 dengan persentase kenaikan setiap tahunnya adalah 8,9\%.

\subsection{Perhitungan pertumbuhan suplai daya} menuju Gardu Induk Nusa Dua

Tabel 3. Data beban transformator

\begin{tabular}{|c|c|c|}
\hline \multirow{2}{*}{ Tahun } & \multicolumn{2}{|c|}{ Suplai Daya (A) } \\
\cline { 2 - 3 } & $\begin{array}{c}\text { GIS Bandara- } \\
\text { Nusa Dua }\end{array}$ & $\begin{array}{c}\text { Pesanggaran- } \\
\text { Nusa Dua }\end{array}$ \\
\hline 2013 & 298,25 & 131,42 \\
\hline 2014 & 72,48 & 269,56 \\
\hline 2015 & 89,47 & 226,86 \\
\hline 2016 & 151,21 & 186,89 \\
\hline 2017 & 158,1 & 248,32 \\
\hline
\end{tabular}

Tabel 3 merupakan data perkembangan beban transformator dari tahun 2013 sampai tahun 2017

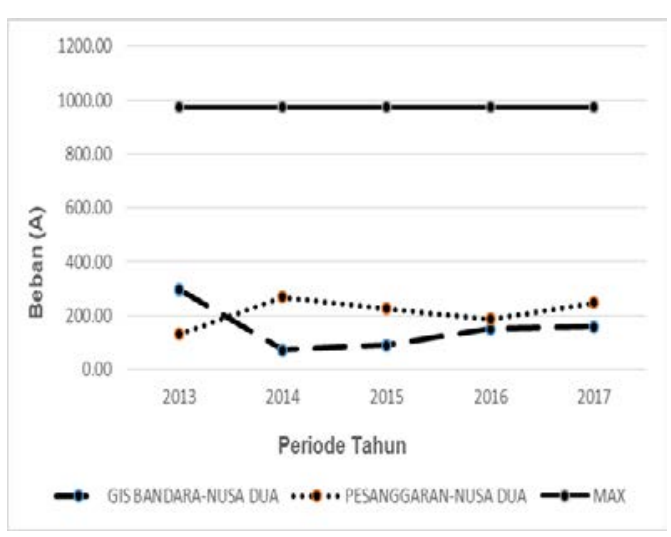

Gambar 5. Grafik suplai daya menuju Gardu Induk Nusa Dua tahun 2013-2017

Gambar 5 merupakan grafik data laju pertumbuhan suplai daya menuju gardu induk Nusa Dua yang disuplai dari GIS Bandara dan GIS Pesanggaran pada tahun 2013-2017.

Nilai perkembangan beban listrik pada tahun pertama dihitung menggunakan persamaan (4).

$$
\begin{aligned}
a & =\frac{\sum_{\mathrm{i}-1}^{\mathrm{n}} \mathrm{Y}_{\mathrm{i}}-\mathrm{B} \sum_{\mathrm{i}-1}^{\mathrm{n}} \mathrm{x}_{\mathrm{i}}}{\mathrm{n}} \\
& =\frac{769,51-8,8(10075)}{5} \\
& =\frac{769,51-89667,5}{5} \\
& =\frac{-88897,99}{5} \\
& =-1779,59
\end{aligned}
$$

Berdasarkan hasil perhitungan laju pertumbuhan transformator menggunakan regresi linear diperoleh persamaan $Y=$ 1779,59+8,9x. Persamaan tersebut dapat dicari beban tiap tahunnya menggunakan persamaan (1) dan hasil perhitungan sampai tahun 2027 ditunjukkan pada Tabel 3.

$$
\begin{aligned}
Y & =a+b x \\
& =-17114,64+8,9(2018) \\
& =-17114,64+17960,2 \\
& =179,61 \mathrm{~A}
\end{aligned}
$$

Tabel 4. Hasil perhitungan suplai daya menuju Gardu Induk Nusa Dua

\begin{tabular}{|c|c|c|}
\hline \multirow{2}{*}{ TAHUN } & \multicolumn{2}{|c|}{ BEBAN SUPLAI SALURAN (A) } \\
\cline { 2 - 3 } & $\begin{array}{c}\text { GIS } \\
\text { Bandara- } \\
\text { Nusa Dua }\end{array}$ & $\begin{array}{c}\text { GIS Pesanggaran- } \\
\text { Nusa Dua }\end{array}$ \\
\hline
\end{tabular}




\begin{tabular}{|l|l|l|}
\hline 2018 & 179,61 & 238,32 \\
\hline 2019 & 188,18 & 246,89 \\
\hline 2020 & 196,75 & 255,46 \\
\hline 2021 & 205,32 & 264,03 \\
\hline 2022 & 213,89 & 272,60 \\
\hline 2023 & 222,46 & 284,17 \\
\hline 2024 & 231,03 & 299,74 \\
\hline 2025 & 249,60 & 317,31 \\
\hline 2026 & 258,17 & 320,88 \\
\hline 2027 & 266,74 & 328,45 \\
\hline
\end{tabular}

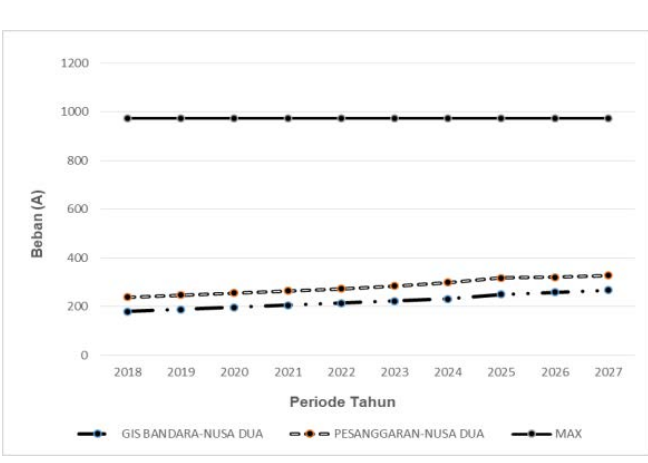

Gambar 6. Grafik hasil perhitungan pertumbuhan sistem transmisi menuju Gardu Induk Nsa Dua

Gambar 6 adalah grafik hasil perhitungan laju pertumbuhan suplai daya menuju Gardu Induk Nusa Dua yang disuplai dari GIS Bandara dan GIS Pesanggaran dengan persentase laju pertumbuhannya adalah 8,9\%.

\subsection{Selisih Perhitungan Antara Pasokan dan Beban}

Selisih perhitungan antara pasokan dan beban dari tahun 2018 hingga tahun 2027 ditunjukkan pada Tabel 5 dan Gambar 7.

Tabel 5. Selisih perhitungan antara pasokan dan beban

\begin{tabular}{|c|c|c|c|}
\hline Tahun & $\begin{array}{c}\text { Selisih } \\
\text { Pasokan } \\
\text { dan } \\
\text { Beban } \\
(\mathrm{A})\end{array}$ & $\begin{array}{c}\text { GIS } \\
\text { Bandara- } \\
\text { Nusa Dua }\end{array}$ & $\begin{array}{c}\text { GIS } \\
\text { Pesanggaran } \\
\text {-Nusa Dua }\end{array}$ \\
\hline 2018 & 43,12 & 18,53 & 24,59 \\
\hline 2019 & 34,55 & 14,94 & 19,60 \\
\hline 2020 & 25,98 & 11,30 & 14,67 \\
\hline 2021 & 17,41 & 7,61 & 9,79 \\
\hline 2022 & 8,84 & 3,88 & 4,95 \\
\hline 2023 & 3,27 & 1,43 & 1,83 \\
\hline 2024 & 1,70 & 0,74 & 0,96 \\
\hline 2025 & 8,07 & 3,55 & 4,52 \\
\hline 2026 & 3,41 & 1,52 & 1,89 \\
\hline
\end{tabular}

\begin{tabular}{|l|l|l|l|}
\hline 2027 & 2,41 & 1,08 & 1,33 \\
\hline
\end{tabular}

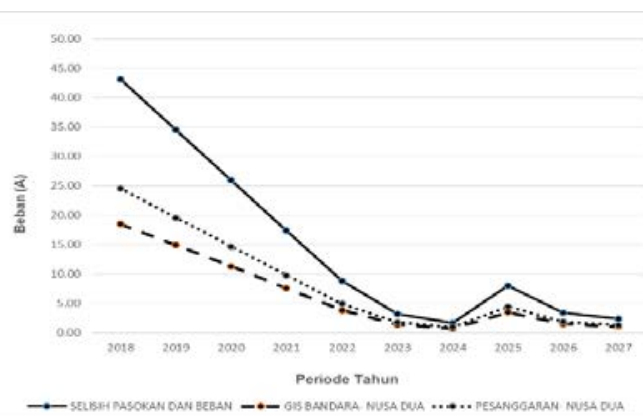

Gambar 7. Grafik selisih perhitungan antara pasokan dan beban

Pasokan dari GIS pesanggaran menuju GI Nusa Dua pada tahun 2018 mencapai 24,59 A kemudian mengalami penurunan setiap tahunnya hingga tahun 2024 losses mencapai nilai terkecil sebesar 0,96 A. Sedangkan pasokan dari GIS Bandara menuju GI Nusa Dua pada tahun 2018 sebesar 18,53 A dan mencapai nilai terkecil sebesar 0,74 A. Dari Gambar 7 dapat dilihat perbandingan besar losses antara GIS Pesanggaran dan GIS Bandara, losses GIS Pesanggaran lebih besar dari losses GIS Bandara. Ini disebabkan karena losses dipengaruhi oleh luas penampang, dan penampang GIS Pesanggaran jaraknya lebih jauh dari pada GIS Bandara.

Sementara itu pada tahun 2025 grafik mengalami kenaikan hingga 8,07 $\mathrm{A}$, disebabkan pada tahun 2025 transformator tidak dapat memikul kenaikan beban, sehingga pada tahun 2025 di Gardu Induk Nusa Dua terjadi penambahan transformator atau pembangunan Gardu Induk baru di wilayah tersebut.

\section{KESIMPULAN}

Berdasarkan hasil perhitungan yang dilakukan dapat disimpulkan bahwa pada tahun 2025 beban pada transformator 3 di Gardu Induk Nusa Dua telah melewati batas kemampuan yang menyebabkan transformator 3 tidak dapat memikul beban pada tahun-tahun berikutnya. Kemampuan Hantar Arus (KHA) penghantar menuju Nusa Dua mampu memasok $80 \%$ dari batas maksimum penghantar itu sendiri. Pasokan dari GIS Bandara ada tahun 2027 adalah 226,742 A dan dari GIS Pesanggaran 328,45 A. 
Keperluan beban yang semakin lama semakin meningkat menyebakan transformator tidak mampu memikul beban yang melebihi batas dari kemampuan transformator itu sendiri. Untuk mengatasi kenaikan beban yang terus meningkat disarankan adanya penambahan transformator baru atau pembangunan Gardu Induk baru di wilayah tersebut, dan melakukan analisis ulang agar mendapat hasil yang lebih signifikan dengan menggunakan metode lainnya.

\section{DAFTAR PUSTAKA}

[1] Pramono, Joko. Dkk. Transmision of Electrical Energy. 2010. Makalah Teknik Tenaga Listrik.

[2] Sau, Matius.2011. Transmisi Daya Elektrik: dilengkapi dengan contohsoal matlab. Makasar: Universitas Kristen Indonesia Paulus. Penerbit: Andi.

[3] Renaldi, A.M.2011. Estimasi Rugi-rugi Energi pada Sistem Distribusi Radial 20 kv menggunakan Metode Energy Load Flow (Tugas Akhir). Jimbaran: Universitas Udayana.

[4] Sriwati. 2013. Prediksi Penggangtian Distribusi Akibat Beban Lebih di Kabupaten Maros. Universitas Islam Makasar. ILTEK. Vol 8. Nomor 15.

[5] Fauzi, J. R 2011. Sisem Proteksi Gardu Induk dan Jaringan150 kV Menggunakan Pemutus Tenaga Media Gas SF^di Gardu Induk 150 kV Kebasan PT. PLN (Persero) P3B JB UPT Tegal (Kerja Praktek). Purbalingga: Universitas Jendral Soedirman.

[6] Febrizal, Y. 2012. Prediksi Kebutuhan Energi Listrik Kota Padang Sampai Tahun 2020. Jurnal Teknik Elektro ITP. Volume. 1, No. 1

[7] Saefulloh Dian. 2013. Perencanaan Pengembangan Gardu Induk Untuk 10 Tahun Kedepan. Jurnal Teknik Elektro Undip.

[8] Gama, N. Aliran Daya Optimal pada Sistem Minahasa. UNSRAT
[9] Ardika, I.M. 2014. Studi Kemampuan Hantar Arus Sistem Transmisi Kelistrikan Bali Tahun 2013-2025 (Tugas Akhir). Jimbaran: Universitas Udayana.

[10] Stevenson, W.D. 1984. Analisis Sistem Tenaga Listrik (Ir. Kamal Idris Pentj). Jakarta ; Erlangga. 